\section{Nursing the Neonate}

\author{
Edited by Helen Yeo, Oxford, \\ Blackwell Science, 1998, 324 pages, \\ $£ 19.99$.
}

History demonstrates that nursing practice has been shaped primarily by medical instruction and never more so than when considering neonatal nursing and ethical aspects of neonatal care.

This book, written by nurses, begins by giving a historical overview of the development of neonatal care from 1960 to the present time. As indicated in the preface much of the text is through necessity dedicated to disease processes: management of respiratory, cardiac, genetic and surgical problems, jaundice and infection. Other topics include: nursing care of the small baby, the critically ill baby and the dying baby; transcultural nursing; community care; stress, and ethical issues in the neonatal unit. A consistent theme throughout the text was the psychosocial needs of parents.

Contributors allude to ethical issues and dilemmas: from the provision of service to extremely low birthweight infants:

"Often these babies die, or if they live their quality of life may be poor, raising ethical questions about treatment. Morale may be low if nurses are not involved in team decisions and feel strongly about certain ethical aspects" (page 289)

to the rights of infants:

"Human beings of all ages, in hospital, have the right to receive the most effective pain relief that can be safely provided" (page 35), and the role of parents as decision makers and providers of care:

"As the baby's condition improves the parents can do more, bathing, cuddling and feeding" (page 77).

However, none of the contributors truly examine the issues surrounding these concepts. It would seem that the physical and emotional "needs" and not the ethical/moral "rights" of infants and their families were considered, for example: "The nurse looking after the baby can usually judge if the parents have such a need" (page 285). It may be that the ethical stance and thus reasoned argument and justification for practice was not the remit of individual contributors. As it was, some authors offered an account which lacked depth and explanation on ethical matters in relation to their particular topic. Perhaps discussion on issues with ethical/moral implications should have been left to the final chapter.

In the last chapter, chapter 16, Ethical issues in neonatal care, Mary Sheenan provides an excellent synopsis of the difficulties in delivering "ethical" care and treatment to patients who are extremely vulnerable and unable consensually to contribute to the process. She tackIes four issues: personhood and assigned value to life; nursing advocacy and conflict; decision making and informed consent, and empowering parents. Each of these topics is reviewed from both a nursing and medical ethics standpoint, but perhaps examples of "everyday practice" could have been utilised to demonstrate nursing dilemmas, for example showing visitors, other than parents and extended family, around the neonatal unit; giving intravenous fluids instead of formula milk in the absence of breast milk, the extended role of the neonatal nurse/midwife and subsequent responsibility and accountability. The topics discussed by Sheenan could have been individual chapters in themselves. However, the interested reader who wishes to delve further into the ethical aspects of neonatal nursing is offered a wellconstructed reading list.

For the most part, this is a good book, giving guidance on basic nursing care as related to pathophysiology. The theme linking each chapter is parent acknowledgment and participation, with an ethical perspective being explored. This reflects the current philosophy of family-centred care within the neonatal environment.

YVONNE FREER

Research Fellow, Simpson Memorial Maternity Pavilion, Edinburgh

\section{Reproducing Narrative: Gender, Reproduction and Law}

Michael Thomson, Aldershot, Hants, Dartmouth, 1998, 228 pages, $£ 40$

(hb).

Thomson's book combines his doctoral research, which began in 1992, with his more recent investigations of the connections between law, constructions of gender and reproductive developments. This publication con tributes to the growing scholarship how gender influences medical dev $\overline{\text { f }}$ opments and the legal response. Medicolegal reproductive discourses an practices exist as influential techno $\sqrt{8}$ gies of gender. These discourses at practices justify and maintain i equalities (page 219). Thomson de scribes how non-reproductive factoos determine reproductive policies atg्भ the ways in which this influences women's autonomy. Also, he demor? strates how non-medical issues are conceptualised as medical, there shifting the locus of power to the medical realm.

Why is this process significant medical ethicists? We must be aware multiple and pernicious factors which create and perpetuate regressive or productive policies. If gender is a regulatory system to maintain aßd legitimate inequality, and if medicor legal reproductive developments ars the "technologies of gender", we mưft understand how they contribute to the oppression of women. To understa the sources of inequality is to combst them.

Thompson exhibits a readine confront complex ethical issues intellectual rigour. In exposinge the externalities which influence repreduction, he explores narratives, p륭ceptions, myths and institutions. Ie identifies that the narratives of genctor represent social relations and this hasa particular significance when reproduction is viewed through the lens medical control. For example, the fir chapter examines how the reprodư tive narrative influenced the criminatsation of abortion in the nineteen century and how non-medical factös were adopted as relevant by the mes. cal anti-abortion campaign. He idenfifies abortion as one of many practices which perpetrated inequality by limifing women's reproductive freedom and economic independence, and their access to employment and highir education.

Thomson draws from international research; Linda Williams's primafy research with Canadian women who have experienced the trauma of 1 in vitro fertilisation is cited and analysed. But Thomson's approach solidly ef phasises the social, economic, a $\mathrm{P} d$ political ethos of the United Kingdom. Drawing from abundant and we्pl referenced sources, he applies femingt theory to women's material and repraductive circumstances, in the tradition of Sue Millns, Jo Bridgeman, Sally Sheldon, and Ellie Lee. 
One of many strengths of Thomson's research is that he makes explicit that which we have intuited, observed, and experienced. First, he analyses those specific socio-economic and political factors which have influenced legislation such as the Abortion Act and the Human Fertilisation and Embryology Act. For example, he questions how conceptions of the aborting woman as "angel or witch, wearied mother or feckless girl, tired housewife or tart" impacted on abortion policies (page 69). Second, he scrutinises industrial fetal policies which maintain traditional sexual divisions. Third, he considers how the image and the concept of the fetus has grown in the abortion debate, eclipsing the primacy of the woman's status.

A few examples will demonstrate the flavour and complexity of Thomson's analysis. The creative references include Peter Greenaway's film The Life of Macon, in which Greenaway reflected upon the sacred and profane power of the iconography of the fetus/ child. Margaret Atwood's novel, The Handmaid's Tale, is mined for insights regarding the "fable warning of the present day objectification of woman as reproducers", which is relevant to the industrial fetal protection analysis. The "monstrous" conception of the female body, as imagined in Mary Shelley's Frankenstein, has contemporary resonance for Thomson: "The female is an object both of desire and of fear, sexual fascination and horror. These associations, of desire and fear, of the monstrous and the necrophilial, have, importantly, been clearly retained and developed within the Frankenstein of film" (page 174).

Thus, Thomson draws from vastly diverse disciplines to illustrate his central thesis; this thesis is relevant for those who contemplate medical ethics because we must acknowledge the powerful ways in which gender influences new reproductive technology and the intervention in the female body more generally.

Thomson provides a balanced analytical approach, which is comprehensively referenced, finely nuanced and eclectic. Consequently, this publication is informative and provocative. Thomson's research is entirely relevant to those medical and legal professionals who rise to the challenge of reflecting upon the social consequences of their own practices and professions.

\section{KATE DIESFELD}

Kent Law School,

University of Kent at Canterbury

\section{Reforming Healthcare by Consent: Involving Those who Matter}

\author{
Edited by Tom Ling, Abingdon, \\ Radcliffe Medical Press, 1999, \\ 235 pages, £22.50.
}

This book is a collection of essays reflecting on the influence and engagement of users in health care development. The word collection feels appropriate here as the essays are very disparate, and without connection, cross-referencing or theming. There are very short chapters (a delightful one by Roy Lilley is only three pages long) but others are many pages long with few subheadings, diagrams or pictures to relieve the reader. (I have to admit like Alice to not enjoying books that "have no pictures or conversation".)

Such is the speed of change in the National Health Service (NHS) that any publication will inevitably be out of date by the time it is published. The introduction acknowledges that the creation of the book has taken a number of years. This is very evident. Some chapters were written after the changes to the NHS were announced in December 1997, but others seem to have been written long before that. We are embarking on a radical change to the NHS and the message from the book is that health care consumers must influence the shape of services. Although the book was published in 1999 and therefore the demise of general practitioner (GP) fundholding was only weeks away, the mention in the first chapter both of fundholding and family health services authorities (which were written out of the NHS several years ago), and only a passing reference to primary care groups in the rest of the book, detracts from that message.

This book does not fully make the case for the ethical imperative of consumer involvement in every corner of health care policy and practice. Many areas are tackled but there are gaps. There is a large endeavour to involve consumers in the whole research agenda, still in its infancy, but this is not mentioned. Nor is the importance of involving consumers in quality (nowhere are the words "clinical governance" mentioned). The tumultuous fallout of the General Medical Council (GMC) hearing of the Bristol doctors is touched on presciently by a couple of authors. But the implica- tions for the relationship between professional and user is not addressed, and there is no mention of the Bristol hearing or its repercussions. It would have also been valuable to have had an international perspective on what is a global issue.

Having said that, there are some wonderful chapters that absorb, challenge and inform. I found the chapters on the role of the pharmaceutical industry and its relationship to the public, Let the industry talk to patients, and the chapter on the lack of consumer involvement in information technology (IT), particularly thoughtprovoking. But with the rather unsystematic approach to a diverse range of issues, you will have to dig deep for gems.

ALISON HILL

Public Health Resource Unit, Oxford

\section{The Birth of Bioethics}

\author{
Albert R Jonsen, New York, Oxford, \\ Oxford University Press, 1998, 431 \\ pages, $£ 37.50$ (hb).
}

What is bioethics? Is it a discipline in its own right or a sub-field of other disciplines such as philosophy, law or theology applied to moral problems in health care? Perhaps the best way to approach this question is to see it as an academic discipline which represents a way of doing ethics somewhere between the logic of moral philosophy and the exigencies of practical policy. Albert Jonsen has written what appears to be the first broad history of bioethics, covering its origins and evolution between 1947 and 1987. According to Jonsen it emerged as a distinct discipline during the 1960s, when various scholars migrated from academic subjects such as law, philosophy and theology, and developed new ways of viewing the traditional ethics associated with medicine. At present bioethics has three professional associations with over 1,000 members and almost 200 centres. Jonsen notes that over 3,500 books and articles on bioethics have been listed. Bioethicists are in great demand by governments and the media, and bioethics commissions and conferences are to be found throughout the world.

In this detailed and widely researched history Jonsen portrays the driving force behind the development of bioethics as the steady accumulation of public concern with the ambiguities generated by scientific develop- 